\title{
Fostering Young Entrepreneurship - The Experiences of a Provincial Government Program
}

\author{
(PRESENTED) \\ Kenneth A.Grant \\ Ted Rogers School of Management \\ Ryerson University \\ Toronto, ON, Canada \\ kagrant@ryerson.ca
}

\begin{abstract}
Encouraging youth entrepreneurship is a focus of governments across the word, with many universities providing programs and courses in entrepreneurship. However, formal education is not enough, the student needs to actually experience the challenges of setting up and running a business. This paper provides a case study of a successful Ontario Government Program called SummerCo, which has enabled over 6,000 student startups over the last 14 years
\end{abstract}

Keywords—youth entrepreneurship, government programs

\section{INTRODUCTION}

Entrepreneurship is one of today's hottest topics. Across the world, there is a widespread recognition that the fostering of entrepreneurship is essential for economic development and progress [1]. In particular, it is well recognised that small to medium-size enterprises (SMEs) are significant creators of economic growth and employment.

While academic initiatives can be identified in the 1970s and 1980s, by the 1990s, at least in the developed world, entrepreneurship had become an acceptable academic discipline [2], albeit one that frequently did not have its own home and pockets of entrepreneurship research and teaching can be found in many different areas of the university, frequently in business schools and sometimes in engineering departments.

More recently in the developing world, the importance of entrepreneurship education and development has also been recognised and received ever-increasing attention. [3]

Many universities have developed and are delivering entrepreneurship courses and programs and some also offer opportunities for students to experience entrepreneurial behaviour, in a variety of field activities and in formal start-up incubators. [4]

Governments in developed and developing economies have also recognised the positive economic impact of the entrepreneur and taken steps to encourage entrepreneurial behaviour. In addition, these countries are also experiencing challenges in finding suitable employment for young people, particularly university graduates, who are also often seen as being underemployed -- that is, taking jobs that do not need a university degree.) [5] Thus, governments are launching youth entrepreneurship programs and are encouraging universities to increase their efforts to educate and graduate students with entrepreneurial knowledge, skills and experience. In China, for example, there are national programs to give every student the opportunity to experience some entrepreneurship education.

There is, however, a widespread belief that entrepreneurship cannot simply be taught, it has to be experienced. [6] For example, the Lean Launchpad frame work, used extensively across the world, has a fundamental focus on "getting out of the office" and discovering and validating customers' interest for the proposed product [7].

Governments have introduced a wide range of programs to assist as piring young entrepreneurs start businesses. This paper presents a descriptive review of one such program - the Ontario Government's long-established Summer Company Program ("SummerCo"). [8]

\section{ABOUT THE PROGRAM}

Ontario is Canada's largest province, with a population of almost 14 million and the provincial government has taken a proactive role in responding to the challenges of youth employment. The provincial Premier has established the Premier's Council on Youth Opportunities, made up of young Ontarians and young professionals, along with some advisers. Its Ministry of Economic Development, Trade and Employment has developed a Youth Job Strategy [9] with a number of initiatives including a Youth Employment Fund to help young people get initial employment, a Youth Innovation Fund and a program called Summer Company that allows young people to get real-world start-up experience.

SummerCo was launched in 2001 and, in its 14 years of operation, has funded almost 6,000 student start-ups. The program has the following key features:

- It operates during the summer break

- It is open to Ontario students between the ages of 15 and 29

- Participants are supported by a local "program provider" that provides general advice, hands-on coaching and mentoring, 
- Applicants submit an online proposal, including a simplified business plan.

- They must commit to spending at least 35 hours a week over the summer period working in the business typically for a period of 9 to 12 weeks

- Students receive a grant of up to $\$ 1,500$ at the beginning for start-up costs and an additional $\$ 1,500$ upon successful completion of the program.

The overall purpose of the program is to raise the awareness of entrepreneurship as a viable career option for the province's youth and teach them the value of entrepreneurial skills in both personal and career endeavours.

\section{METHODOLOGY FOR THE STUDY}

This descriptive paper has been prepared using published reports and other background material provided to the researcher by the Ministry as well as preliminary analysis of survey data obtained by the Ministry as a post-program requirement for all participants. The Ministry also provided the researcher with access to survey data from 2013 and 2014.

\section{HOW THE PROGRAM OPERATES}

\section{A. The Local Program Provider}

Students work with a local program provider, of which there are some 60 across the province, including voluntary organis ations, entrepreneurship centres, community groups and universities. The program provider helps the students prepare their application and, if the student is successful, then provides review, mentoring and coaching throughout the program.

\section{B. The Application}

Students apply online by registering and submitting a business plan. The business plan is a simplified version of a more traditional business plan with the students being required to provide:

\section{- Executive Summary/Business Idea}

- Description of the Product or Service

- Marketing Plan (addressing customers, prices and sales, advertising and other promotion)

- Operating Requirements and Costs

- Employees Needed

- Regulations to be Followed

- Success and Safety Planning (risk assessment)

- $\quad$ Start-up Budget, including investment needed

- Cash Flow Statement

\section{Launching and Running the Business}

Although no specific numbers are available, a Ministry representative indicated that almost all of the properly completed applications were approved (the program provider is closely involved in the application process and effectively does the initial screening).

Participants receive training from the program provider, and meet with a mentor at least four times. They also have a site visit from the program provider. They are expected to follow the program guidelines and meet all legal requirements to set up and operate a business in Ontario. During the summer they are expected to maintain a daily activity journal in an online system provided by the Ministry, covering such things as time allocation, business tasks, operations and marketing activities.

They receive up to $\$ 1,500$ at the beginning of the program to be spent within 30 days on the qualifying items described in the application. (In essence these are the as sets need to launch the business.)

\section{End-of-summer Activities}

At the end of the summer (the program ends on September $\left.1^{\text {st }}\right)$ participants are require to carry out a number of end-ofprogram activities, mostly with their program provider, including:

- Attending an exit interview

- Confirming that they are returning to school

- Providing copies of their financial records

- Completing, anonymously, an online participant survey.

Once these have been done, the participant is then eligible to receive the second payment of up to $\$ 1,500$

\section{KEY RESULTS FROM THE PROGRAM}

The secondary data provided by the Ministry provide a comprehensive picture of the program throughput its evolution. Formal reviews of the program, including surveys of former participants took place in 2008 (for 2001 to 2007, covering 1,591 startups and 635 post program survey responses $(40 \%$ response)) [10] and 2014 (for 2007-2012, covering 3,187 startups and 703 post program survey responses $(23 \%$ response)) [11].

In addition the researcher obtained summary end-ofprogram survey data for the years 2006-2012 and detailed surveys for 2013 and 2014, completed by about $90 \%$ of the participants. While there were some methodological differences between each of these studies, there is enough consistency to allow a comprehensive cross -program analys is.

\section{A. Participant Background and Influences}

From 2001 to 2012 , close to $60 \%$ of participants were male and most participants were under 25. As Table 1 indicates, there has been a shift towards slightly older students in the last few years. 
TABLE I AGE RANGE OF PARTICIPANTS

\begin{tabular}{|l|l|l|}
\hline Age Range & $2001-2007$ & $2007-2012$ \\
\hline Under 19 & $43 \%$ & $37 \%$ \\
\hline $19-24$ & $51 \%$ & $39 \%$ \\
\hline Over 24 & $6 \%$ & $24 \%$ \\
\hline
\end{tabular}

A majority of participants had had previous exposure to business/entrepreneurship. They knew someone who started their own business, most often family members, and/or had taken some previous form of education or training in business/entrepreneurship prior to SummerCo. A smaller number (about 10\%) had previous experience starting and running their own business.

In addition, about half indicated that they already had a business idea that they knew would make money, and this played a role in their decision to apply to the program.

\section{B. The Types of Business}

Table 2 shows the types of business started from 2006-2014.

Of the 4,562 start-ups examined from 2006-2014, just over $50 \%$ were service businesses, with $17 \%$ being retail businesses Other business types included technology, hospitality/foods, construction, agriculture, manufacturing, wholesale/distribution, tourism and import export. The 2014 review reported generally similar percentages.

\section{The Business Performance}

For 2013 and 2014, Participants reported on actual versus projected results. Overall, while individual performance varied significantly, most did not achieve their anticipated levels of performance, with sales averaging about half of those projected and profit at about one third of projections. Average sales were $\$ 4,751$. While about $73 \%$ had revenues of $\$ 5,000$ or less, some earned over $\$ 20,000$, with more than $80 \%$ making a profit. The average profit margin was $36 \%$.

Interestingly, the 2008 study found that the average annual sales revenue for post-SummerCo continuing businesses was about $\$ 38,000$, with an average of 2.7 employees, with new

\begin{tabular}{|c|c|c|}
\hline Types of Business Started & Number & \\
\hline \multicolumn{2}{|c|}{ 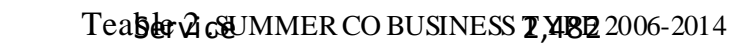 } & $54 \%$ \\
\hline Retail & 756 & $17 \%$ \\
\hline Technology & 339 & $7 \%$ \\
\hline Hospitality/Foods & 276 & $6 \%$ \\
\hline Construction & 198 & $4 \%$ \\
\hline Agriculture & 192 & $4 \%$ \\
\hline Manufacturing & 189 & $4 \%$ \\
\hline Wholesale/Distribution & 58 & $1 \%$ \\
\hline Tourism & 54 & $1 \%$ \\
\hline Import/Export & 18 & $0 \%$ \\
\hline Total & 4,562 & 1.00 \\
\hline
\end{tabular}

startups by the participants averaging about $\$ 56,000$, with an average 5.4 employees )

\section{PROGRAM IMPACT}

\section{A Post-Program Entrepreneurial Behaviour}

The 2008 and 2014 surveys examined the participants' activities after program completion. Key findings were:

\section{- Employment status:}

- About half were still taking part in some form of schooling

- About one third were self-employed

- For those not in school, only about 3\% from 2001-7 were unemployed (compared to the provincial youth average of $13 \%$ in 2007)

\section{- Startup Status}

- A substantial proportion continued their SummerCo business (22\% for those in 2001-7, 43\% for 2007-12)

- Participants also started new businesses (22\% of those who participated for 2007-12)

- Participants also reflected on the personal impact of participation with over $90 \%$ reporting they had learned useful skills and that the knowledge and experiences gained impacted their future selfemployment decisions.

- Virtually all (99\%) would recommend the program to others)

\section{Economic Impact}

Both the 2008 and 2014 studies attempted to measre the economic impact, using quite different methodologies.

- Total Business Revenue: in 2007, the continuing SummerCo businesses had about $\$ 11.4$ million in sales revenue according to the 2001-2007 study [10], with the 2007-2012 study [11] estimating the cumulative revenue from 2007 to 2012 to be about 30.5 million.

- Jobs created: The 2001-2007 study found that the ongoing SummerCo and additional businesses started had 874 emp loyees. From 2007 to 2012 an estimated 1,276 full-time jobs and 1,702 part-time jobs were created.

Given the different measurement approaches taken, the two sets of figures cannot be compared directly, but each indicates that the post-program activity has produced a significant direct economic impact, whether measured by revenue or jobs created.

\section{CONCLUSIONS}

Overall, the program has been successful since its beginnings in 2001, growing steadily, from 180 startups in 2001 to 849 in 2014 . It has had a significant economic impact, 
although it can be argued that this was, in some ways, an exceptional sample group, many of whom were very likely to

However, it might also be argued that participating in the program increased the likelihood of their success.

Participants were almost universal in their praise of the program, crediting it with improve their skills, not only for startups, but for life in general. The post program reviews showed that many have continued their Su mmerCo or started a new business and that, as a group they are much less likely to be unemployed than their peers.

\section{REFERENCES}

[1] Naudé, W. Entrepreneurs and economic development, United Nations University, April 23, 2011, retrieved May 1, 2015 from: http://unu.edu/publications/articles/are-ent repreneurial-societies-alsohappier.html

[2] Kourilsky, M.L.(1995) Entrepreneurship Education: Opportunity in Search of Curriculum, Center for Entrepreneurial Leadership, Kauffman Foundation

[3] Volkmann, C., Wilson, K.E., Mariotti, S., Rabuzzi, D., Vyakarnam, S. \& Sepulveda, A. (2009) World Economic Forum Educat ing the Next have started their own business even without the program,

Wave of Entrepreneurs: Unlocking entrepreneurial capabilities to meet the global challenges of the 21 st Century -- A Report of the Global Education Initiative, World Economic Forum, Switzerland, April 2009

[4] Ma, J. (2013) Student Entrepreneurship Is Humming At Elite Universities, Forbes Magazine May 14, 2013

[5] Schawbell, D. (2014) Why College Students Need to Be Entrepreneurial With Their Careers, Entrepreneur Magazine, April 1, 2014

[6] Osborne, S. (2015) Young people need to know that entrepreneurship is hard, Harvard business review, April 6,2015

[7] Blank, S. \& Dorf, B. (2012) The Startup Owner's Manual, The Stepby-Step Guide for Building a Great Company, K\&SRanch Inc

[8] Government of Ontario (2015) Summer Company Program Guidelines 2015

[9] Government of Ontario (n..d) Making an Impact, Youth Job Strategy: Part of Ontario's Strategy for Jobs and Growth, https://dr6j45jk9xcmk.cloudfront.net/document s/704/youth-jobsstrategy-en.pdf

[10] R.A. Malatest \& Associates Ltd. (2008) Summer Company Outcomes Study - Final Report, April $29^{\text {th }}, 2008$

[11] Prairie Research Associates (2014) SummerCo Evaluation - Final Report, April 30 $0^{\text {th }}, 2014$ 